\title{
What Is Electoral Psychology?-Scope, Concepts, and Methodological Challenges for Studying Conscious and Subconscious Patterns of Electoral Behavior, Experience, and Ergonomics
}

\author{
Sarah Harrison $(D$ \\ Department of Government, London School of Economics and Political Science, London WC2A 2AE, UK; \\ s.l.harrison@lse.ac.uk
}

Received: 10 December 2019; Accepted: 14 February 2020; Published: 19 February 2020

\begin{abstract}
Electoral psychology is defined as any model based on human psychology that is used to explain any electoral experience or outcome at the individual or aggregate level. Electoral psychology can also be an interface with other crucial aspects of the vote. For example, the interface between electoral psychology and electoral organization constitutes electoral ergonomics. The very nature of the models tested in electoral psychology has also led scholars in the field to complement mainstream social science methodologies with their own specific methodological approaches in order to capture the subconscious component of the vote and the subtle nature of the psychological processes determining the electoral experience and the way in which it permeates citizens' thoughts and lives. After defining electoral psychology, this introductory article scopes its analytical roots and contemporary relevance, focuses on the importance of switching from "institution-centric" to "people-centric" conceptions of electoral behavior, and notably how it redefines key concepts such as electoral identity and consistency, and approaches questions of personality, morality, memory, identity, and emotions in electoral psychological models. Then, it discusses some of the unique methodological challenges that the field faces, notably when it comes to analyzing largely subconscious phenomena, and addresses them, before explaining how the various contributions to this Special Issue give a flavor of the scope and approaches of electoral psychology contributions to electoral studies.
\end{abstract}

Keywords: Electoral psychology

\section{What is Electoral Psychology?}

The last decade has been quite unique when it comes to elections and electoral results across world democracies. A number of outcomes have shocked much of the world from the victory of "Leave" in the UK referendum on membership of the European Union of 23 June 2016 to the election of Donald Trump as US President in November of the same year, not to mention the coalesced victory of the Lega and the Five Star Movement in Italy in March 2018, or on the polar opposite end of the "liberal centrism" scale, that of Emmanuel Macron as French President in May 2017.

Perhaps less obvious, but equally novel, many countries have returned hung parliaments or seemingly ungovernable legislatures across the Western world, for example, two hung parliaments in a mere seven years in the UK (2010 and 2017) in a system more aligned to straightforward one-party majorities, with another general election to be held in December 2019. Similarly, unexpected volatility resulted in hung parliaments in Sweden and Australia, in 2010. Moreover, during recent months, a series of multiple highly contested elections have plagued government formation in Spain and in Israel, in 2019, where parties failed to form agreements and the electorate was called to the polling stations with an unprecedented regularity. 
At the same time, there has been several instances of surprisingly democratic good news. The inevitable pessimism that arose from the assumption that electoral turnout was on a progressively permanent decline was also met with concerns about the participation of young people in particular. However, turnout in the 2019 European Parliament elections (a typical prototype of a second order election) unexpectedly surpassed all previous levels since the 1980s, as did youth turnout in the 2016 EU membership referendum, and again in the 2017 UK General Elections. Indeed, youth turnout will be a focal point in the forthcoming General Election on 12 December 2019.

The relevance of these counter-intuitive electoral phenomena is not purely historical, but analytical as well. As they occur, researchers increasingly realize that the models we use in much of the existing electoral research are ill-equipped to explain some of these paradoxes and that there is something about the individual and collective psychology of contemporary democratic voters across a whole variety of political systems that needs to be reintegrated into our approaches if we are to make sense of current electoral realities.

This is where electoral psychology becomes relevant. It is defined as the use of any model based on human psychology to explain any electoral experience or outcome at the individual or aggregate level [1]. The human psychology determinants notably include personality, morality, memory, emotions, cognition, persuasion, and identity. The electoral experiences and outcomes focus in particular on participation, overall turnout, electoral choice and outcomes, the nature and connotations of the electoral experience (when, how, with whom, and with what thought people vote), electoral attitudes (including hope and hopelessness), perceptions of the electoral atmosphere, individual interpretations of context, election cycles, projections, and decision-making processes including timing, stability, habituation, and transformation, and a sense of electoral resolution or lack thereof. Electoral psychology can also be an interface with other crucial aspects of the vote. For example, the interface between electoral psychology and electoral organization constitutes electoral ergonomics.

Beyond the unique range of questions that electoral psychology addresses, the very nature of the models it tests has also led scholars in the field to complement mainstream social science methodologies with their own specific methodological approaches in order to capture the subconscious component of the vote and the subtle nature of the psychological processes that determine the electoral experience and the way in which it permeates citizens' thoughts and lives. These methods range from diaries and panel studies to visual, physiological, and field experiments.

The multiple references to the psychology of voters and its shrouded mystery, the role of personality, memory, emotions, and electoral ergonomics are intrinsic to the study of electoral psychology and is the collective concern of this Special Issue. Here, authors who have largely defined the field of electoral psychology and its central concepts focus on analytical or empirical puzzles of contemporary electoral psychology.

This introductory overview delineates the field, its analytical focus, its conceptual perspectives, and its signature methodologies. It also explains where electoral psychology sits in the broader landscape of electoral and behavioral sciences and draws commonalities with and differences from alternative approaches. It also explains the logic of the different contributions that are presented in this Special Issue and what they collectively tell us about the psychology of voters.

\section{Analytical Roots and Contemporary Relevance of Electoral Psychology Approaches}

In a world of ever-increasing political uncertainty and growing dissatisfaction, the question of what voting means to citizens and what emotions people experience at the very moment when they exercise their right to vote is perhaps more important than ever before. In studies of electoral psychology, we assess the act of voting, a unique moment of civic communion between a citizen and his or her political system, and try to understand the long-term development of a voter's psychology and identity, and the way it acquires its consistency and logic throughout a citizen's life, from childhood to death. One of the paradoxes of voting behavior in the current context is that most existing socioeconomic models typically explain why different individuals support one party or another, however, this assumes 
that citizens are defined by an electoral choice. In addition, recent research by Bruter and Harrison suggested that $20 \%$ to $30 \%$ make up or change their minds within a week of the elections and that $29 \%$ of Americans and $40 \%$ of French voters changed their mind on the day of an election [1]. This insight into the very nature of the dynamics of electoral behavior and decision making requires us to reconsider the way in which we understand the mind of a voter.

The study of voting behavior is rich in exciting contributions. Modern studies of political behavior can be traced back to the research by Lazarsfeld and the Columbia school in the 1940s [2,3]. The Columbia model promoted the use of surveys as the obvious method of electoral investigation and quickly tailored their model towards a sociological understanding of the vote. Another resounding triumph for the political psychology approach came with the Michigan model and The American Voter, a seminal piece which many still recognize as one of the most influential books in the history of political science [4,5]. Campbell et al. put partisan identification at the heart of citizens' political behavior. Their model suggests that for reasons including socialization, social class, and environment, voters identify with a political party. This partisan identification is the "baseline" of the vote, and as such combines with voters' evaluations of short-term factors (candidates' personalities, incumbent's record, issues, etc.) to produce an electoral decision.

However, while political scientists have long perceived the need to understand the psychological mechanisms behind voters' attitudes, recent developments in political science have dedicated proportionally more attention to political sociology and political economy approaches and to electoral context than to psychological analyses of the vote. In the 1950s, Lane insisted that the role of individual personality on the vote was somewhat overlooked, and he would likely reach similar conclusions today [6]. Furthermore, our understanding of psychological models of the vote remains more than sociological and economic alternatives. In sociological and economic terms, we know "dominant" models though must account for exceptions. By contrast, in electoral psychology, we often study exceptions but lack dominant models delineating the psychological leitmotiv behind citizens' electoral behavior. The cognitive and emotional processes underlying the vote have often been paradoxically neglected as compared with social and demographic determinism or rational electoral preferences. Perhaps, the frontal opposition between cleavage-based and rational choice theories has left little space for distinct psychological models to develop.

The centrality of partisan identification in psychological models of political behavior persisted in further influential studies such as Butler and Stokes, who refined the Michigan model of socialization, environment, and electoral change [7]. Partisan identity remained the centerpiece of all behavior, capable of absorbing most psychological and sociological paths to electoral choice. In both works, the electoral identity of a citizen is equal to (or essentially superimposed with) their partisan identity. However, their approach arguably overlooks essential questions about what elections represent. Partisan identification models limit the concept of electoral consistency to the relatively "superficial" level of partisanship. While this might—at a stretch—-have made sense in an era of aligned politics, identity and consistency could register at a much deeper level (a certain "conception" of politics, values, relationship between citizens and the state or as we shall see, role of a voter) which could be entirely dissociated from partisanship, notably in de-aligned contexts $[8,9]$.

\section{Redefining Voter Consistency and Identity}

The context of dealignment is an excellent example of how the electoral psychology approach entirely changes the way electoral science looks at apparent electoral change or anomalies. From the point of view of partisan-centric models such as those described above, which Bruter and Harrison described as taking an "institutionalist view" of behavior, voters that move away from partisan alignments represent change and a citizen who votes for different parties at different points in time can come across as anomalous or incoherent unless one finds an institutionalist reason for their behavior (such as split ticket voting or second order election models) [1], from an electoral psychological point of view, however, this need not be the case. A citizen who votes for the left in the 1980s and switches 
to the extreme right in the 2000s is not necessarily incoherent. Instead, there is almost certainly a psychological basis for internal consistency that is not accounted for by party-centric models. Is it inconceivable that a floating voter who chooses new parties, or switches back and forth with every incumbent disappointment, can express a coherent electoral identity (unrelated to partisanship) and exhibit a form of systematic behavior? Even Campbell and Miller had to consider the possibility that split-ticket voting could be intentional and part of a purposeful coherence [5,10-12].

In fact, from an electoral psychology point of view, it would be inconceivable to consider de-aligned voters as an anomaly or unexplainable, and not just because of the ample literature identifying the likely nature of realigned or de-aligned voters [13-15]. While partisan identification could still work in the simplified US party system, research in European electoral behavior faces complex definitions of electoral choice itself, often replacing party choice by propensity to vote (for example, [16-19]). In this context, the psychological consistency of voters must go beyond partisanship.

Indeed, electoral psychology has been more about reclaiming psychological models of the vote away from institutional focus in favor of true behavior-centrism. For example, in the Michigan model of the vote, partisan identification is considered a deeply held psychological trait, or indeed, an " identity" [4]. In addition, conceptually, given psychological insights into identity, it is hard to intuitively imagine partisanship as a foundational identity, and citizens only exceptionally refer to parties in their identity discourse [20]. Additionally, the analytical doubts surrounding the notion of a partisan model of identity does not mean that a (non-partisan) electoral identity does not exist and matter. Therefore, psychological approaches to behavior have progressively emancipated from partisan identity models, to dissociate electoral psychology from this iconic heritage, for instance, conceiving an alternative electoral identity based on the perceived role of a voter instead [1]. This concept pertains to the largely subconscious understanding of our role as a voter, including a referee/supporter model and empathic displacement, such as the link between the individual, collective, and societal dimensions of the vote.

One of the fundamental aspects of the study of electoral psychology refers to personality, which encompasses traits, personality derivatives, morality, and sociotropism. Alongside personality, memory is also a critical facet that is essential to the understanding of electoral behavior and attitudes. This includes the assimilated recollection of sensorial perceptions and experiences from our childhood and first vote, to recent elections regardless of whether we choose to participate or not.

While psychological approaches to elections do not undermine the usefulness of sociological and economic approaches to the vote, they introduce crucial elements such as personality, cognition (for instance memory), emotion, and an identity to models of political behavior, and dramatically filter, condition, and modify the impact of sociological or rational predictors. Bruter and Harrison push this rationale further and insist that in order to truly understand the nature of the psychology of voters, we must consider a triple inter-related dependent variable, that is, electoral behavior, electoral experience, and electoral resolution [1]. In this respect, they studied the emotionality of the electoral experience alongside electoral choice and participation and assessed the conditions in which elections lead to reconciliation or conversely create divisions and feed hostility.

\section{Memory, Personality, and the Vote}

Existing research such as that by Atkinson and Shiffrin and Squire illustrate that memory and identity are also likely to shape future behavior [21,22]. These studies show how memory is constructed, mobilized, and able to affect human behavior consciously and subconsciously. The Atkinson and Shiffrin model suggests that memory stems from three different types of registers, visual, auditory, and haptic [21]. Therefore, we remember the things we see, hear and say, or "touch" (physically experience). This distinction is important to understand potential sources of electoral memory. In the short term, memories are stored through a sequence of rehearsal, coding, decision, and retrieval before potentially being transferred into the long-term memory. Squire argues that long-term memory can be expressed in either a declarative (explicit) or a non-declarative (implicit) manner [22]. The former relies on remembering facts and events, while the latter relates to the assimilation of skills and habits, priming 
effects, classical conditioning, and non-associative learning. Therefore, electorally, we dissociate between explicit memories (what voters recall from the past) and implicit mechanisms (unconscious habits and conditionings that voters reproduce). Finally, Bayliss et al. highlight three memory stages, the encoding (registration) of information, its storage (maintenance over time), and its retrieval (access through recognition, recall, or implicit reproduction) [23]. These insights capture the complex itinerary of an electoral image from experience to memory and its retrieval and mobilization in future elections.

Historically, political scientists who have focused on memories of electoral choice have found that $10 \%$ to $20 \%$ of respondents misreport their choice [24-26]. Price et al. suggest that misrepresentation and rationalization based on the expected future vote is actually far more frequent [27]. Thus, many political scientists believe that citizens do not remember past elections. However, in the Atkinson and Shiffrin model, for example, electoral decision is neither an auditory, visual, nor haptic stimulus. Memories of past thought processes exist if they are salient but not otherwise and not when the mental process is subconscious. Moreover, visual memory of election adverts or election night, auditory memory of discussions or arguments, and haptic memories of the polling station experience could all exist simultaneously. Consequently, the experience of participating in an election should not be limited to the study of electoral choice, but should also involve an understanding of the rituals, feelings, and democratic interaction that also characterize this infrequent act of communion with the political system.

Bruter and Harrison revealed some interesting findings regarding the electoral memory of citizens [1]. They reported that some recollections of elections are very "physical", for example, the impact of station location or the atmosphere during the campaign, on election day or even on election night. For example, $79 \%$ of US citizens remember images from election night. Citizens often recall specific elections citing infamous scandals or unexpected outcomes. In this respect, $94 \%$ of French voters remember 2002. Other memories are often individualized, for example, personal discussions about the election with friends and family members, or even arguments or disputes about the election. Memories of early electoral experiences are also incredibly important. Eighty-two percent of Americans recall the first election when they were eligible to vote, and 70\% remember an election during their childhood years. This echoes the unique nature of the electoral psychology of young people [28].

Memories of elections are highly consequential for young citizens' participation. Bruter and Harrison showed that an early experience of elections significantly increases propensity to participate [1]. In the USA, $48 \%$ of citizens that recall accompanying their parents to the polling station have voted in an election, while only $30 \%$ of those with no such memory have voted in an election. Furthermore, young people who do not go to vote in the first two elections that they are eligible to vote in are likely to become long-term habitual abstentionists.

In the 1960s and 1970s, the traditional alignment models of Lipset and Rokkan were subjected to the scrutiny that accompanied electoral change and increasingly volatile party systems [29]. As a result, a number of scholars started questioning the impact of personality on behavior. Greenstein dedicated his work to the impact of personality and the limits of "political personality" studies within political science [30]. While most of his work focused on leaders (US Presidents) rather than voters, he reported that personality does matter in politics. However, psychologists frequently fail to agree on the fundamental concept of "personality" and how it should be measured and operationalized. For example, Smith, Bruner et al. considered "opinions" to be part of the personality concept [31], while Caprara, Schwartz et al. expanded their model to include "values" [32]. Di Palma and McClosky highlighted the importance of conformity [33], and Sniderman and Lane preferred to view ideology as an extension of personality [6,34]. Most political scientists including Peterson et al. and Gosling et al. use the so-called "Big Five" personality traits, i.e., extraversion, agreeableness, conscientiousness, emotional stability, and openness to experience $[35,36]$. Some authors prefer to refer to the "big-three" or "alternative-five" personality traits [37] and Caprara, Schwartz et al. used discrete traits, friendliness, openness, energy, and conscientiousness, alongside specific values [32]. Research conducted by Boyle, Stankov et al. questioned the salience of the Big Five in that these specific traits account for only about half of normal personality characteristics [38], while Zillig, Hemenover et al. [39] and Paunonen and 
Jackson [40] highlighted various key, and often deeper, personality traits that the schema of the Big Five do not encompass. Bruter and Harrison preferred to use a broader spectrum of personality traits that included elements of the "Big Five" such as openness to experience and extraversion, alongside discrete traits such as personal rigidity, aversion to risk, aversion to change, sense of alienation, empathy, individualism, and long-term projection [1]. They also found that moral hierarchization has a significant impact on the electoral experience, attitudes, and behavior of citizens across democracies.

\section{Elections and Emotions}

Despite significant efforts [41,42] to bring emotions into political analysis, the study of emotions and elections is still relatively limited within the political science literature. Marcus et al. criticize the normative tendency of studies of emotions in the democratic literature and question their role in politics [43]. By contrast, the emotional nature of political experiences and behavior is highlighted by studies that show that identities are intrinsically twinned with emotions $[20,41,44]$ and indeed in electoral campaigns and communication [45]. While emotions and reason are often described as the head and heart of a voter, recent research has moved away from perceiving emotion as purely affective, to suggest that there is instead a consistent interaction between them. Specific emotions such as hope, pride, sympathy, disgust, anger, and fear are used by the National Election Study to assess respondents' characterization of US Presidential candidates [46]. Similarly, Lazarus focuses on the following six fundamental emotions: anger, guilt, fear (anxiety), sadness, hope, and happiness [47]. Moreover, Bruter and Harrison emphasize the crucial role of emotions as symptoms of electoral experience and capture them throughout the various "moments" of the electoral process [1]. They also find that elections tend to be far more emotional for many citizens than often assumed, including those who do not care about politics.

They notably show that elections can be a tearful experience for many citizens. Their findings show that $25 \%$ of Americans have already cried because of an election and an overwhelming $63 \%$ say that election night makes them feel emotional. In the UK, a third of voters reported having tears in their eyes on the night of the 2016 referendum on the UK's membership of the EU, a proportion reaching nearly half among young people aged 18 to 24 . Across elections and contexts, on election day itself, $60 \%$ feel excited in the polling booth, $74 \%$ feel proud, whereas $53 \%$ also say that it makes them feel worried. Harrison confirms the particular vividness of the emotion of young voters [28].

As a result, emotions cannot be conceived as exogenous causes of electoral choice but can be interpreted as intrinsic markers of electoral experience. Thus, feeling happy, excited, emotional, or worried in the election is part of the electoral experience itself, an outcome of the democratic process, likely to both shape and be shaped by electoral behavior and closure. These contextualized emotions are, thus, seen to be influenced by a voter's identity, memory, and personality, and by electoral ergonomics and atmosphere.

\section{Methodological Challenges}

The substantive scope of electoral psychology, discussed in previous sections, implies some specific and complex methodological challenges which often exceed those of other aspects of political science in general and the field of electoral behavior in particular.

To start with, the focus on elements such as personality, memory, identity, and ergonomic effects make it extremely difficult to rely on self-reporting, whereas most political experience and behavior obey largely subconscious mechanisms. For example, even perfectly honest respondents cannot accurately tell us how they feel when they vote, why they vote as they do, or what dominates their electoral experience, because they are bound by the limits of their own knowledge and beliefs, which ignores their preponderantly subconscious logic. Lakoff and Johnson underline the immense preponderance (over 90\%) of subconscious effects in political communication, and beyond in human behavior [48]. In addition, numerous neurological studies have shown that over $95 \%$ of a human decision is subconscious, and therefore taking self-reporting at face value is intrinsically problematic [49]. 
As noted by Bruter and Harrison, while most political analysis include some subconscious components as either sources or consequences, or mechanisms of political behavior, electoral psychology is the only approach to prominently feature subconscious elements at all three of these levels [1]. Indeed, while people are never directly conscious of their own personality or the significance of their memory, neither would a conscious characterization of one's emotions or experience ever be a sufficient and accurate measure of them. Therefore, this prominence of the subconscious in all aspects of electoral psychology models is the first foundational challenge of electoral psychology research which, as we will discuss, imposes a need for measures which cannot solely be based on self-reporting.

A second difficulty pertains to the articulation between generalizable mechanics and idiosyncratic narratives in electoral psychological reality which has typically had a greater focus in multimethod approaches mixing quantitative and qualitative components in most existing electoral psychology research as compared with other fields of the discipline.

Third, the nature of the dependent variables of interest in electoral psychology creates a need to understand complex dynamic causation without narrowly timed occurrence of dependent outcomes. In other words, whereas most electoral research focuses on electoral choice as the main or sole endgame of electoral patterns, electoral psychologists tend to focus on a much broader web of emotions, experiences, and behavior that can span multiple election cycles and constitute multiple layers of reciprocal causation or subsequent effects. This implies an almost infinite superimposition of short, medium, and long-term mechanisms often requiring complex and theoretically driven modeling of dynamic causation.

Let us now consider the three methodological challenges in turn. First, the need to balance self-reported and observational data is not frequently discussed but arguably is even more important. It relates to the importance of subconscious mechanisms in human (and electoral) behavior. While there is a generic case to be made to explore the subconscious, the risk of conscious distortion is particularly strong in electoral studies if only because most citizens only know of electoral opinion research in the context of election polls, the measurement of citizens' preferences, and the prediction of electoral results. While this is a respectable field, its goals, foci, and methodological requirements differ from academic research, and over decades of electoral polling, democratic citizens have undoubtedly developed a strong sense of how polling results get interpreted by and affect elite behavior. We also need to strive for a balance between static and dynamic approaches in a bid to entangle cyclical effects and look at their durability and consistency over time.

\section{A Sample of Electoral Psychology Enquiries}

Drawing upon the conceptual, methodological, and substantive scopes and challenges of electoral psychology described above, this Special Issue highlights a sample of cutting-edge approaches and scientific enquiries that are symptomatic of the field.

The following series of contributions define and discuss key concepts in electoral psychology. Eri Bertsou provides an excellent contribution to the discussion of the concept and measurement of distrust. Using qualitative evidence drawn from three national contexts to map the concept and its evaluative dimensions, his findings show that political distrust is entwined with the failure of representation and entails a fundamentally ethical dimension. Michael Bruter's article defines the concept of electoral ergonomics as the interface between electoral psychology and electoral design. This contribution investigates the psychological effects that different types of electoral organization can have on electoral experience in terms of personality, memory, emotions, and identity. Using two case studies, he shows that young people seem more likely to vote for radical right parties if they vote using a postal ballot than in person at the polling station based on panel study evidence from the UK. The second example is derived from an experiment that tracks the deliberation time that citizens take when they are asked to vote using materialized or dematerialized mono-papers or poly-paper ballots. Carol Galais and Andre Blais offer an application of electoral psychological mechanisms by analyzing the role of gender in perceptions and effects of the duty to vote. They use empirical data to 
test the role of political interest and moral predispositions on the observed gender gap. Their findings confirm a significant but small gender difference in favor of men. In addition, they suggest that this could be due to lower levels of political interest reported by women than men. Finally, Sarah Harrison discusses the concept, nature, and consequences of democratic frustration. Using insights from the psychology literature, this contribution introduces and operationalizes the concept of democratic frustration to shed new light on pathologies of democratic crises. Specifically, it suggests that citizens become frustrated when a perceived democratic delivery deficit interacts with a strong democratic expectation or desire. The article tests this model using two original surveys run in the UK during the 2017 General Election and the 2019 European Parliament elections.

Each contribution performs a different role highlighting key aspects of what electoral psychology is as an emerging subfield of study in electoral behavior and the wider political science discipline. Eri Bertsou's, Michael Bruter's, and Sarah Harrison's articles present new crucial concepts in the field which include distrust, electoral ergonomics, and democratic frustration. In particular, the latter is also unique in that it shows how electoral psychology can use insights from the psychology literature to shed new light on political science and political behavior questions. Michael Bruter's contribution specifically evaluates the interaction between electoral psychology and institutional design. Carol Galais's and Andre Blais's article is unique in that it analyses how an electoral psychology pattern can differ by citizens' characteristics, in this case, gender, Finally, Eri Bertsou's article is special in that it highlights how electoral psychology sometimes takes concepts "upside down" to change our insights on political behavior. Overall, the contributions each differ in their methods and approaches. Each of the elements is critical and without any one of them, the presentation of what electoral psychology is as a field of research and how it innovates conceptually, methodologically, and crossdisciplinarily would be deeply incomplete.

Altogether, therefore, these contributions enable us to better understand the unique scope, challenges, approaches, and methods in electoral psychology, showcasing key methods from surveys and experiments to interviews and highlighting fundamental concepts which add new visions to the battery of more traditional variables historically used in the field of electoral science, since the 1950s.

Conflicts of Interest: The authors declare no conflict of interest.

\section{References}

1. Bruter, M.; Harrison, S. Inside the Mind of a Voter: A New Approach in Electoral Psychology; Princeton University: Princeton, NJ, USA, 2020.

2. Lazarsfeld, P.F.; Berelson, B.; Gaudet, H. The People's Choice. How the Voter Makes up his Mind in a Presidential Campaign; Columbia University Press: New York, NY, USA, 1944.

3. Berelson, B.R.; Lazarsfeld, P.F.; McPhee, W.N. Voting: A Study of Opinion Formation in a Presidential Campaign; University of Chicago Press: Chicago, IL, USA, 1954.

4. Campbell, A.; Converse, P.; Miller, W.; Stokes, D. The American Voter; University of Michigan Press: Ann Arbor, MI, USA, 1960.

5. Campbell, A.; Miller, W.E. The motivational basis of straight and split ticket voting. Am. Political Sci. Rev. 1957, 51, 293-312. [CrossRef]

6. Lane, R.E. Political personality and electoral choice. Am. Political Sci. Rev. 1955, 49, 173-190. [CrossRef]

7. Butler, D.; Stokes, D. Political Change in Britain: Forces Shaping Electoral Choice; Palgrave Macmillan: Basingstoke, UK, 1969.

8. Franklin, M.N.; Mackie, T.T.; Valen, H. Electoral Change: Responses to Evolving Social and Attitudinal Structures in Western Nations; Cambridge University Press: Cambridge, UK, 1992.

9. Dalton, R.J. Political cleavages, issues, and electoral change. In Comparing Democracies: Elections and Voting in Global Perspective; LeDuc, L., Niemi, R.G., Norris, P., Eds.; Sage: Thousand Oaks, CA, USA, 1996; pp. $319-342$.

10. Alvarez, R.M.; Schousen, M.M. Policy moderation or conflicting expectations? Testing the intentional models of split-ticket voting. Am. Politics Q. 1993, 21, 410-438. [CrossRef] 
11. Lewis-Beck, M.S.; Nadeau, R. Split-ticket voting: The effects of cognitive Madisonianism. J. Politics 2004, 66, 97-112. [CrossRef]

12. Bruter, M.; Harrison, S. Enjoying political participation: Findings on the psychology of voters and the emotions associated with participation in eight democracies. In Proceedings of the Keynote Conference, New York, NY, USA, 4-5 March 2011.

13. Arcuri, L.; Castelli, L.; Galdi, S.; Zogmaister, C.; Amadori, A. Predicting the vote: Implicit attitudes as predictors of the future behavior of decided and undecided voters. Political Psychol. 2008, 29, 369-387. [CrossRef]

14. Schoen, H. Voting behavior and public opinion. In Concise Encyclopedia of Comparative Sociology; Sasaki, M., Goldstone, J., Zimmermann, E., Sanderson, S.K., Eds.; Brill: Leiden, The Netherlands, 2014; pp. 360-369.

15. Dalton, R.J.; Flanagan, S.E. Electoral Change in Advanced Industrial Democracies: Realignment or Dealignment? Princeton University Press: Princeton, NJ, USA, 2017.

16. Van der Eijk, C.; Franklin, M. (Eds.) Choosing Europe? University of Michigan Press: Ann Arbor, MI, USA, 1996.

17. Van der Eijk, C.; Franklin, M.; Marsh, M. What voters teach us about Europe-wide elections: What Europe-wide elections teach us about voters. Elect. Stud. 1996, 15, 149-166. [CrossRef]

18. Van der Brug, W.; van der Eijk, C.; Franklin, M. The Economy and the Vote: Economic Conditions and Elections in Fifteen Countries; Cambridge University Press: Cambridge, UK, 2007.

19. Déloye, Y.; Bruter, M. (Eds.) Encyclopaedia of European Elections; Palgrave Macmillan: Basingstoke, UK, 2007.

20. Bruter, M. Citizens of Europe? Palgrave Macmillan: Basingstoke, UK, 2005.

21. Atkinson, R.C.; Shiffrin, R.M. Human memory: A proposed system and its control processes. Psychol. Learn. Motiv. 1968, 2, 89-195.

22. Squire, L.R. Declarative and nondeclarative memory: Multiple brain systems supporting learning and memory. J. Cogn. Neurosci. 1992, 4, 232-243. [CrossRef]

23. Bayliss, D.M.; Jarrold, C.; Baddeley, A.D.; Gunn, D.M. The relationship between short-term memory and working memory: Complex span made simple? Memory 2005, 13, 414-421. [CrossRef]

24. Himmelweit, H.T.; Biberian, M.J.; Stockdale, J. Memory for past vote: Implications of a study of bias in recall. Br. J. Political Sci. 1978, 8, 365-375. [CrossRef]

25. Shachar, R.; Shamir, M. Estimating vote persistence sources without panel data. Political Anal. 1996, 6, 107-124. [CrossRef]

26. Granberg, D.; Holmberg, S. Prior behavior, recalled behavior, and the prediction of subsequent voting behavior in Sweden and the US. Hum. Relat. 1986, 39, 135-148. [CrossRef]

27. Price, V.; Tewksbury, D.; Powers, E. Switching trains of thought: The impact of news frames on readers' cognitive responses. Commun. Res. 1997, 24, 481-506. [CrossRef]

28. Harrison, S. Young voters in the general election 2017. Parliam. Aff. 2018, 71, 255-266. [CrossRef]

29. Lipset, S.M.; Rokkan, S. (Eds.) Party Systems and Voter Alignments: Cross-National Perspectives; Free Press: New York, NY, USA, 1967.

30. Greenstein, F. Children and Politics; Yale University Press: New Haven, CT, USA, 1965.

31. Smith, M.B.; Bruner, J.S.; White, R.W. Opinions and Personality; John Wiley: New York, NY, USA, 1956.

32. Caprara, G.V.; Schwartz, S.; Capanna, C.; Vecchione, M.; Barbaranelli, C. Personality and politics: Values, traits, and political choice. Political Psychol. 2006, 27, 1-28. [CrossRef]

33. Di Palma, G.; McClosky, H. Personality and conformity: The learning of political attitudes. Am. Political Sci. Rev. 1970, 64, 1054-1073. [CrossRef]

34. Sniderman, P.M.; Forbes, H.D.; Melzer, I. Party loyalty and electoral volatility: A study of the Canadian party system. Can. J. Political Sci. 1974, 7, 268-288. [CrossRef]

35. Peterson, R.S. A directive leadership style in group decision making can be both virtue and vice: Evidence from elite and experimental groups. J. Personal. Soc. Psychol. 1997, 72, 1107-1121. [CrossRef]

36. Gosling, S.D.; Rentfrow, P.J.; Swann, W.B., Jr. A very brief measure of the Big-Five personality domains. J. Res. Personal. 2003, 37, 504-528. [CrossRef]

37. Zuckerman, M.; Kuhlman, D.M.; Joireman, J.; Teta, P.; Kraft, M. A comparison of three structural models for personality: The big three, the big five, and the alternative five. J. Personal. Soc. Psychol. 1993, 65, 757-768. [CrossRef] 
38. Boyle, G.J.; Stankov, L.; Cattell, R.B. Measurement and statistical models in the study of personality and intelligence. In International Handbook of Personality and Intelligence; Saklofske, D.H., Zeidner, M., Eds.; Plenum: New York, NY, USA, 1995; pp. 431-433.

39. Zillig, L.M.P.; Hemenover, S.H.; Dienstbier, R.A. What do we assess when we assess a Big 5 trait? A content analysis of the affective, behavioral, and cognitive processes represented in Big 5 personality inventories. Personal. Soc. Psychol. Bull. 2002, 28, 847-858. [CrossRef]

40. Paunonen, S.V.; Jackson, D.N. What is beyond the big five? Plenty! J. Personal. 2000, 68, 821-835. [CrossRef] [PubMed]

41. Neuman, W.R.; Marcus, G.E.; MacKuen, M.; Crigler, A.N. Theorizing Affect's Effects. In The Affect Effect: Dynamics of Emotion in Political Thinking and Behavior; University of Chicago Press: Chicago, IL, USA, 2007; pp. 1-20.

42. Rosema, M. The Sincere Vote: A Psychological Study of Voting. Ph.D. Thesis, University of Twente, Leiden, The Netherlands, 2004.

43. Marcus, G.E.; Neuman, W.R.; MacKuen, M. Affective Intelligence and Political Judgment; University of Chicago Press: Chicago, IL, USA, 2000.

44. Britt, L.; Heise, D. From shame to pride in identity politics. In Self, Identity, and Social Movements; Stryker, S., Owens, T., White, R., Eds.; University of Minnesota Press: Minneapolis, MN, USA, 2000; pp. 252-268.

45. Brader, T. Campaigning for Hearts and Minds: How Emotional Appeals in Political Ads Work; University of Chicago Press: Chicago, IL, USA, 2006.

46. Kinder, D.R.; Peters, M.D.; Abelson, R.P.; Fiske, S.T. Presidential prototypes. Political Behav. 1980, 2, $315-337$. [CrossRef]

47. Lazarus, R.S.; Lazarus, R.S. Emotion and Adaptation; Oxford University Press: Oxford, UK, 1991.

48. Lakoff, G.; Johnson, M. Metaphors We Live By; University of Chicago Press: Chicago, IL, USA, 2003.

49. Dewey, J. Human Nature and Conduct; Courier Corporation: Chelmsford, MA, USA, 2002.

(C) 2020 by the author. Licensee MDPI, Basel, Switzerland. This article is an open access article distributed under the terms and conditions of the Creative Commons Attribution (CC BY) license (http://creativecommons.org/licenses/by/4.0/). 